\section{FÜR SIE GELESEN}

Journal Club

\title{
Homöopathie greift nicht bei Asthma
}

\author{
Gleiches mit Gleichem behandeln ist ein Grundprinzip der \\ Homöopathie. Kinderärzte haben jetzt getestet, was passiert, \\ wenn man allergisches Asthma mit dem auslösenden Allergen \\ in homöopathischen Dosen behandelt.
}

keine Differenzen bezüglich der objektiv quantifizierten Lungenfunktion.

Fazit: Diese Studie ist nur eine in einer Reihe kürzlich publizierter Studien, die keine Wirksamkeit der homöopathischen Asthmatherapie aufzeigten. Es handelt sich um eine Studie ohne Kontrollgruppe. Derartige Untersuchungen sind methodisch vor allem deswegen angreifbar, weil sie dazu neigen, falsch positive Ergebnisse zu liefern. Da das Ergebnis der vorliegenden Studie jedoch negativ ist, greift diese Kritik nicht. Interessant ist, dass ein ähnliches

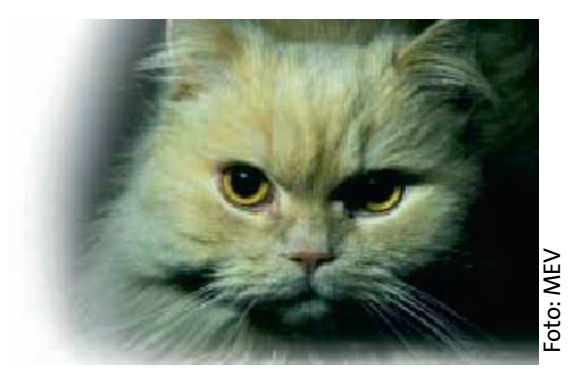

Katzenhaare in homöopathischen Dosen bringen Katzenhaarallergikern keine wirkliche Erleichterung.

Therapieschema - streng genommen handelt es sich nicht um Homöopathie, sondem um Isopathie - von einer britischen Arbeitsgruppe wiederholt als effektiv ausgewiesen wurde. In Homöopathikerkreisen gehören diese britischen Untersuchungen wegen ihrer konsistent positiven Resultate und ihres hohen Standards zu den „Vorzeigestudien" der Homöopathie. Die vorgestellte Arbeit sät hier allerdings erhebliche Zweifel.

Li AM et al. Homeopathy in childhood asthma. Thorax 2003; 58: 826.

\section{Mehr als nur Histaminblockade}

\section{In der chemisch heterogenen Gruppe der $\mathrm{H}_{1}$-Antihistaminika finden sich auch Substanzen, die über zusätzliche antiallergische Wirk- mechanismen verfügen. Zu diesen Verbindungen gehört Ebastin, das vor allem bei saisonaler allergischer Rhinitis und chronischer Urtikaria eingesetzt wird.}

$\mathrm{D}$ ie antiallergische Wirksamkeit von Ebastin wurde bisher überwiegend auf seinen $\mathrm{H} 1$-antagonisierenden Effekt zurückgeführt. Ein japanisches Forscherteam suchte jetzt in vitro nach weiteren antiallergischen Mechanismen der nicht sedierenden Substanz.

Im Vordergrund standen dabei die T-Zell-Proliferation, die Zytokinproduktion durch co-stimulierende Signale bestimmter T-Zell-Oberflächenproteine, die T-Zell-Migration sowie die Produktion von proinflammatorischen Zytokinen durch Makrophagen. Alle diese Vorgänge sind bekannte Triggerfaktoren für allergische Entzündungsreaktionen. Als Vergleichssubstanz diente der H1-Antagonist Ketotifen. Beide Substanzen wurden an den peripheren
T-Zellen von gesunden Probanden getestet.

Ebastin blockierte die T-Zell-Proliferation und die Synthese von IL-4, IL-5, IL-6 und TNF- $\alpha$ durch die TZellen unter dem Einfluss verschiedener co-stimulatorisch wirksamer Substanzen. Die Produktion von IL-2 und IFN- $\gamma$, den beiden Leitzytokinen der TH1-Zellantwort, blieb dagegen unbeeinflusst. Außerdem verhinderte Ebastin die T-Zell-Migration und die Produktion von proinflammatorischen Zytokinen wie TNF- $\alpha$ und IL- 6 durch Makrophagen. Unter Ketotifen wurden diese Wirkungen nicht beobachtet.

Die Ergebnisse weisen auf einen bisher für Ebastin noch nicht beschriebenen inhibitorischen Effekt auf die
TH2-Zell-vermittelte Zytokinproduktion hin. Die zusätzliche Hemmung der T-Zell-Migration und die Synthesehemmung proinflammatorischer $\mathrm{Zy}$ tokine durch T-Zellen und Makrophagen lässt einen Einsatz von Ebastin bei T-Zell-vermittelten allergischen Erkrankungen wie Asthma oder atopischer Dermatitis denkbar erscheinen. Zumindest theoretisch, so die Autoren, komme die Substanz aufgrund ihrer blockierenden Wirkung auf die Produktion von TNF- $\alpha$ und IL- 6 auch als Kandidat für der Therapie von Erkrankungen wie rheumatoider Arthritis oder Morbus Crohn in Frage.

Fazit: Ebastin zeigt über eine H1-antagonistische Wirkung hinaus in vitro zusätzliche antiallergische und antiinflammatorische Effekte wie beispielsweise die Synthesehemmung TH2Zell-spezifischer und proinflammatorischer Zytokine.

$b k$

Nori $\boldsymbol{M}$ et al. Ebastine inhibits T cell migration, production of Th2-type cytokines and proinflammatory cytokines. Clin Exp Allergy 2003; 33: 1544-54 